\title{
Nocturia as a marker of poor health: Causal associations to inform care.
}

\author{
WF Bower ${ }^{1}$, DM Whishaw ${ }^{2}$, F Khan $^{1}$ \\ ${ }^{1}$ Department of Rehabilitation Services \\ ${ }^{2}$ Departments of Aged Care and Urology, Royal Park Campus, Royal \\ Melbourne Hospital, 34-54 Poplar Road, Parkville. VICTORIA. 3052. \\ AUSTRALIA
}

Corresponding author: Dr WF Bower, Email: wendy.bower@mh.org.au Telephone: 619 83872194

Abstract

\begin{abstract}
Aims
Nocturia is a common symptom of many conditions and is encountered in patients presenting to services across different medical specialities and health disciplines. The causal pathway of nocturia is multi-factorial and differs between patients. There is currently no symptomspecific clinical algorithm for all-cause diagnosis of nocturia. The aim of this study was to investigate the interrelationships between causes of nocturia in order to inform the development of a comprehensive multidisciplinary assessment metric.
\end{abstract}

\section{Methods}

A PubMed search that identified studies reporting relationships between nocturia and a priori aetiological factors was conducted by cross referencing the term 'nocturia' with 'polyuria, postural hypotension, hypertension, cardiac function, heart failure, depression, anxiety, polypharmacy, sleep disturbance, sleep disorder, apnoea, and lower urinary tract symptoms'. Directed acyclic graphs (DAGS) were constructed to visually represent causal assumptions and to identify underlying relationships.

\section{Results}

This study confirmed that causality of nocturia can be expressed in a directed acyclic graph, with the key variables being cardiovascular dysfunction, polyuria, sleep disturbance, mental health, metabolic and inflammatory changes, health status and lower urinary tract symptoms. None of the variables were independently a sufficient or necessary direct cause 
of nocturia and multiple backdoor pathways exist to nocturnal voiding. Polypharmacy, increasing age and BMI all have confounding effects.

\section{Conclusions}

There are significant interactions between voiding at night and metabolic, cardiovascular, hormonal, mental health, sleep and inflammatory changes that flag nocturia as a likely marker of co-morbid poor health. Patients should be comprehensively evaluated for allcauses of nocturia since multiple aetiologies commonly co-exist.

\section{Introduction}

Nocturia, the act of waking from sleep in order to void, affects both men and women equally throughout the life span, although the overall prevalence increases with age (1) (2). The symptom is classified by the number of times an individual wakes each night to void (3). In a pooled analysis nocturia once per night was noted in up to $93 \%$ of men older than 70 years and in $77 \%$ of similar aged women (4). Arising twice or more per night to void affects around $60 \%$ of both men and women older than 65 years; however, the number of episodes can fluctuate over time $(5,6)$.

Nocturia is a common symptom of many conditions, for example congestive heart failure, metabolic disorders, urinary incontinence, anxiety and autonomic dysfunction and has a significant association with renal and malignant disease (7) (1) (8). The causal pathway is multi-factorial and differs between patients (9). Nocturia is a co-existing symptom in patients presenting to services across medical specialities who are assessed by different health professionals. There is currently no symptom-specific clinical pathway for nocturia (10).

Sleep disturbance is often associated with nocturia frequently reducing time in restorative slow wave sleep. Sleep fragmentation is known to produce daytime fatigue, impaired cognitive function, psychomotor performance and safety issues. Nocturia has been associated with compromised glucose homeostasis, reduced nocturnal plasma melatonin levels, increased catecholamine levels and a high risk of using sedatives (11).

Falls, experienced by one third of older people, are the leading cause of emergency department presentations, hospitalizations and injury-related death (12-14). In residential care falls are often related to attempts at independent toileting (15) whilst in hospital falls appear to occur more between the hours of 2 and $4 \mathrm{am}$ than at any other time interval. Falling and nocturia may share causal variables aside from environmental factors. 
The costs associated with nocturia are significant. Direct costs of nocturia accrue from greater utilisation of primary health care, chronic disease management, emergency care and hospitalisation for morbidity. Medical costs and hospitalization days are increased up to threefold for patients with nocturia even after adjustment for age, sex and known diseases or risk factors (16).

Personal costs relate to compromised wellbeing. Table 1 cites older people reporting frustration, a negative impact on quality of life, inconvenience and reduced function as a result of nocturia (17). Psychosocial impact is further evidenced by social withdrawal. Waking twice was the threshold for bother (9) (18). In men presenting to urology services, nocturia was perceived as the most bothersome of lower urinary tract symptoms (LUTS), whilst at a population level it followed urgency and stress incontinence as the most concerning LUTS (19).

Despite the obvious impact of nocturia, patients appear to believe the symptom is trivial and not worth reporting (20). Raising the issue does not guarantee a cure; patients with lower urinary tract symptoms who responded to treatment generally report only a modest reduction in nocturia episodes not appreciably different from placebo (10).

Nocturnal polyuria and the lower urinary tract symptoms of overactive bladder, cystitis and benign prostatic hypertrophy are extensively investigated causes of nocturia (21-24) (1, 2527). The aim of this study was to explore the association between nocturia and markers of impaired health outside the urinary tract, including variables known to be associated with falling. Directed acyclic graphs, a structured way of presenting an overview of causal relationships within context, were used to summarise possible pathways between nocturia and specified variables. A secondary aim was to detect multiple contributing morbidities and common causes (i.e. confounding) that may guide a comprehensive evaluation of nocturia.

\section{Materials and Methods}

A literature search, following Cochrane recommendations was undertaken to identify studies describing describing the relationships between nocturia of $>1 /$ night and markers of poor health (28). Electronic databases MedLine, CINAHL, Web of Science, Cochrane, EMBASE, as well as relevant conference abstracts and meeting proceedings were examined. The search was limited to articles published in English between the years 2004 and 2015 on the basis that reviews of the pathogenesis of nocturia have been published within the last decade. Studies 
described subjects of both genders who were 60 years or older. Search strategies cross referenced the terms 'nocturia, polyuria, postural blood pressure, hypertension, cardiac function, cardiovascular disease, diabetes, depression, cognitive impairment, polypharmacy, sleep disturbance, sleep disorder, apnoea, lower urinary tract symptoms, inflammation, falls and falling'.

A total of 85 papers were identified as potentially relevant to the study and were retrieved in full. Of these, three were systematic reviews, two were topic reviews and 28 did not report risk rate data. The remaining 52 papers were reviewed in full and established to be eligible for inclusion in the study (see Appendix 1).

In each paper risk ratios and 95\% Confidence Intervals were identified for individual comorbidities of nocturia, as stratified by frequency of episodes, and extracted to a data sheet. Associations between falling ( \pm sustaining a fracture) and nocturia were similarly tabularised. Where multiple studies reported the same associations the highest and lowest risk statistics were tabulated for the summary tables in this paper.

Risk data, along with epidemiological information drawn from studies, was used as a priori knowledge to construct directed acyclic graphs (DAG) summarising the causal pathways underlying nocturia and also the effect of nocturia and falling on the outcome of early death. Confounding variables were identified on the DAG and met the criteria of being a risk factor for the outcome, associated with, but not a consequence of, the exposure.

\section{Results}

Table 2 details the risks of specific groups of comorbidities known to be related to poor health in patients with nocturia of varying severity.

Mental health: It can be seen that there was an increased odds of depression with a higher number of night voids in both genders. After the age of 60 years this risk was significant with nocturia more than once per night. This risk was maintained when socioeconomic, demographic and comorbidity variables were included in the model (3 voids per night men: 2.24 95\% CI 1.15-4.34; women: 1.94 95\% CI 1.21-3.13; 2 voids in men OR 2.08 95\% CI 1.11-3.92). In community-dwelling females, nocturia was the only urinary symptom significantly associated with clinical depression whilst in women with urological symptoms stratified by sleep interference the adjusted OR was 3.37 (95\% CI 1.63-6.94). 
Use of antidepressant medication was not associated with incident nocturia, however, use of SSRI medication was significantly more common with $\geq 2$ nocturnal voids than in subjects with no awakening (OR Male: 5.4 95\% CI 1.5-19.7; Female: 3.6 95\% CI 1.1.5-8.6).

Moderate or high anxiety was significantly associated with $\mathrm{a} \geq 3$ times risk of nocturia at least twice per night. Both depression (as indicated by antidepressant use) and anxiety were significantly associated with falls (OR 3.3 and 2.39 respectively in older institutionalised individuals.

Higher cognition was protective for nocturia and the variable was retained in a multivariate analysis of correlates of nocturia $(0.64,95 \%$ CI $0.46-0.88)$. Similarly higher educational achievement in older women was protective for nocturia (OR $0.9495 \%$ CI 0.86-0.99). Cardiovascular: Hypertension was twice as likely in subjects with nocturia and was retained in a model of nocturia $\geq 2$ alongside use of a diuretic and older age. A systematic review reported a significant association between hypertension and nocturia in 11 of 14 identified studies. Hypertension did not appear to be a predictor of incident nocturia. Mean pulse pressure (systolic minus diastolic pressure) readings were significantly higher in fallers versus non fallers, but not different in the presence versus absence of nocturia.

Heart failure was not significantly associated with nocturia $\geq 2$, however, lower limb oedema in women doubled the risk of nocturia and was retained in a gender-specific multivariate model for night voiding. Leg oedema was also retained as a non-independent predictor in a model of nocturnal polyuria in men (OR of $1.5195 \%$ CI 0.69-3.3). Diuretic medication was unrelated to nocturia in men, and also in women after adjustment for age, race and rural status. Heart failure with symptoms was significantly associated with falling episodes: OR 1.5 and 2.6 for occasional and frequent falling respectively. Use of diuretic medication was not a significant factor in the association between nocturia and falls.

Metabolic: Diabetes Mellitus carried a risk of 2.62 (95\% CI 1.40-4.92) $\geq 2$ voids per night and 1.67 (0.82-3.39) for waking once to void. Diabetes Mellitus was a significant independent predictor of nocturia in a sample of 60-80 year old men and women and along with frequency of nocturia significantly predicted sleep disturbance. Hypertension (OR 1.53 95\% CI 1.022.27), coronary heart disease (OR 1.75 95\% CI 1.03-2.96) and stroke (OR 2.19 95\% CI 1.223.95) were predictors of nocturia in diabetic subjects. Diabetes Mellitus conferred a 2.25 (1.21-4.14) risk for falling in older people. 
Vitamin D deficiency $(<20 \mathrm{ng} / \mathrm{mL})$ was significantly more common in men with, rather than without, nocturia ( $\mathrm{p}=0.01$ ). Data for women only reported a decreased risk of urinary incontinence or multiple lower urinary tract symptoms (LUTS) when Vitamin D levels were normal compared to subthreshold $(\mathrm{p}=0.022)$. Low serum testosterone levels $(<2.5 \mathrm{ng} / \mathrm{mL})$ were an independent predictor of nocturia of at least twice per night (OR 1.6 95\% CI 1.012.53).

Inflammation: The inflammatory marker C-reactive protein $(\mathrm{CRP})>0.81 \mathrm{mg} / \mathrm{L}$ was significantly associated with nocturia $\geq 2$ (OR $1.6495 \% \mathrm{CI} 1.18-2.27)$. The risk ratios for the middle CRP tertile and nocturia were also significant in women (OR 2.00 95\% CI 1.39-2.87). Arthritis was a significant risk factor for frequent nocturia (OR $1.5195 \%$ CI 1.08-2.05) in men but not women.

Sleep: Severity of nocturia was associated with greater impairment on the global sleep assessment, frequency and degree of snoring and increased drowsiness. Snoring was reported to have the highest sensitivity for nocturia in men and second highest after obesity in women. Nocturia severity was an independent predictor of the apnea-hypopnea index measured at sleep centres. Obstructive sleep apnea in women was a significant predictor of nocturia $\geq 2$ (OR 4.99 95\% CI 2.49-10.0) and was retained in a multivariate analysis (OR 2.9 95\% CI 1.29-6.52). There was a significant relationship between falls and daytime sleepiness that was modified by nocturia but sustained after adjustment for night voiding (OR 2.63 95\% CI 1.31$5.30)$.

Insomnia was independently predicted by nocturia (OR $1.7595 \%$ CI 1.31-2.35), depression (OR 2.49 95\% CI 1.61-3.87), stroke (OR 2.28 95\% CI 1.06-4.89) and arthritis (OR 1.85 95\% CI 1.35-2.55). Difficulty returning to sleep after voiding was independently predicted by cardio/cerebrovascular morbidity and primary sleep disorders (sleep disordered breathing or restless leg syndrome). Restless leg syndrome was significant associated with nocturia $\geq 2$ $3.06(1.31-7.32)$ in both genders.

Health status: Health variables not significantly associated with nocturia included being underweight, moderately overweight (body mass index 25 to 29), waist circumference > $102 \mathrm{~cm}$, an history of urinary tract infections, alcohol use, former and current smoking in men and former smoking in women, caffeine intake, angina, coronary artery disease and myocardial infarction, arrhythmia, late menopause, parity and obstetric history, stroke and malignant or respiratory disease. Moderate or high levels of physical activity, higher 
cognition in men, more advanced education level in women, high nocturnal melatonin secretion and a maximum voided volume over $450 \mathrm{~mL}$ were protective for nocturia.

Mortality: Nocturia $\geq 2$ was associated with reduced survival. Age-gender adjusted risk for death in patients with nocturia $\geq 2$ was 1.91 (95\% CI 1.07-3.43). The Charleston Comorbidity Index was retained as an independent predictor of mortality in older subjects with nocturia (HR 1.44 95\% CI 1.21-1.71) whilst coronary heart disease (CHD) had an interactive effect with nocturia, in predicting mortality (HR $1.7895 \%$ CI 1.10-2.88). After 12 months, nocturia of $\geq 2$ was significantly associated with early death in $74.5 \%$ of fallers versus $53.6 \%$ of nonfalling community dwelling older people.

Table 3 clarifies that nocturia sub-classified by severity carried a significant risk of falling. Subjects with nocturia $\geq 3$ had a relative risk of 1.27 for an index fall (95\% CI 1.01-1.60) despite adjustment for slow gait and diabetes mellitus. Nocturia was one of the six strongest predictors of future falls and fractures in community-dwelling individuals over 65 years of age. The cumulative incident rate of fall-related fracture was significantly higher in patients with nocturia $\geq 2$ than in patients who voided less (OR 2.01 95\% CI 1.04-3.87).

The causal pathways of nocturia are summarised in a chronological DAG in Figure 1 whilst Figure 2 summarises the common causes of falling and nocturia $\geq 2$. Individual causes are unlikely to be sufficient or necessary to produce nocturia since there are multiple backdoor pathways.

\section{Discussion}

This study has presented evidence for the existence of multiple relationships between nocturia and non-lower urinary tract markers of impaired health. There are significant interactions between voiding at night and metabolic, cardiovascular, hormonal, mental health, sleep and inflammatory changes that flag nocturia as a likely marker of co-morbid medical conditions. These findings accord with opinions expressed over the last five years in which nocturia is being considered outside the category of a storage lower urinary tract symptom and presented instead as a sign of systemic disease $(27,29,30)$.

Symptoms indicative of cardiovascular, endocrine, immunological, cognitive and psychological impairment and sleep disorders were all significant risk factors for nocturia of at least twice a night. In general larger risks were reported for $\geq 2$ voids per night. From our 
data search the greatest risks attached to frequent nocturia were noted in women with disordered breathing at night, individuals either using sedative hypnotics or complaining of secondary insomnia who also reported falls, women with a poor health status, anxiety or impaired cognition as a co-morbid diagnosis in either gender, the presence of both restless leg syndrome and secondary insomnia and men with elevated inflammatory markers. These disparate comorbidities suggest the possibility of nocturia phenotypes beyond the aetiologies of polyuria and a nocturnally overactive bladder.

The potential for twice the risk of early death in patients with frequent nocturia is sobering, as is the increased risk of cardiovascular or cerebrovascular morbidity and malignant disease (8, $31,32)$. In summarising the health risks associated with nocturia this study suggests that it is improbable that any one variable causes nocturia or is required for the symptom to develop. This is in agreement with findings from a Finnish study that reported no single variable affected $50 \%$ or more of men with nocturia whilst in women multiple correlates were predictive of night voiding (18).

This study has demonstrated that causal variables associated with nocturia are also on the pathway for falls and that waking at night to void multiple times is likely to confer a direct effect on the outcome of falling. Patients with nocturia have a markedly increased risk of injurious falls; when followed up for six months the risk of a fracture doubled (15). Conversely, falls are predictive of long term mortality in patients with nocturia but not in those who sleep through the night. NICE Guidelines for Falls Risk assessment pathway currently omits the evaluation of nocturia, including only daytime bladder symptoms related to incontinence (33).

The probabilistic tool, DAG, was selected to examine causality of nocturia in this study since it can be used to explore causal inference among a number of random variables. The visual nature of the graph facilitates communication of complex material which is simplified by the left to right chronology. The DAG summarising the causal pathway of nocturia shows complex interactions including a number of backdoor pathways. Use also highlighted the presence of confounding on both the outcome of nocturia and early death. Whilst identification of these variables is important for the analysis phase of a nocturia study, in that that they should be stratified or adjusted for, there are always additional unknown causes. With the exception of drug therapy, such as diuresis or antipsychotic medication, no other single variable on our DAG was a necessary or sufficient individual cause of nocturia. 
No causality can be implied from data presented in this study particularly given that the direction of associations may differ between variables and patients. It is possible though that health profiles might be grouped on the basis of interacting risk variables generating nocturia phenotypes. For example males at mid-life with a large neck circumference having sleep disordered breathing clearly differ from women with pitting lower leg oedema and coexisting poor sleep efficiency.

Current practice in urology and continence services is to obtain a 3 day Frequency Volume Chart, prostate symptom score, urinalysis (and possibly urine culture), uroflowmetry and estimate bladder emptying efficiency. Some authors suggest screening for hours slept before first night void and measuring health-related quality of life $(34,35)$. Data from this study suggest such evaluation of nocturia may not uncover all causes of the symptom. These findings concur with the recent statement that " the medical profession is not currently well placed to offer effective screening ... for most patients with nocturia" (30).

\section{Conclusions:}

The implications of this study are that patients who admit to nocturia should be comprehensively evaluated for all-causes of the symptom with the expectation that multiple causes may co-exist within one patient. This should include assessment of health issues traditionally beyond the scope of lower urinary tract evaluation symptomatology. An allcause diagnostic pathway would include cardiovascular and metabolic status, blood pressure profile, fluid shift into the lower limbs, sleep apnoea and insomnia, mental health disorders and related pharmacotherapy, immune suppression, autonomic dysfunction, cognition and polypharmacy. Falls and fall-related injuries would also be noted.

Future work should be translational and include development of a comprehensive specialised metric for use in patients with nocturia as both an incidental finding and a primary reported symptom. Such a tool would extend beyond consideration of nocturia as a lower urinary tract symptom and instead contextualise it as a marker of health status. Patients with nocturia present across disciplines and medical specialties and typically receive care for individual disorders rather than inter-disciplinary input. Development of an all-cause metric would potentially improve practice and smooth inequalities associated with current care of patients with co-morbid nocturia. 
Disclaimer: The research time of WB has been supported by grants from both The

Australian Bladder Foundation and Ferring Pharmaceuticals.

\section{References}

1. Bing MH ML, Jennum P, Mortensen S, Lose G. . Nocturia and associated morbidity in a Danish population of men and women aged 60-80 years. . BJU Int 2008;102(7):808-14; discussion 14-5.

2. Temml C, Ponholzer A, Gujahr G, Berger I, Marszalek M, Madersbacher S. Nocturia is an age-independent risk factor for hip fractures in men. Neurourol and Urodyn 2009;28(8):949-52.

3. Cornu J-N, Abrams P, Chapple CR, Dmochowski RR, Lemack GE, Michel MC, et al. A contemporary assessment of nocturia: definition, epidemiology, pathophysiology, and management-a systematic review and meta-analysis. Europ Urol 2012;62: 877-90

4. Bosch J, Weiss JP The prevalence and causes of nocturia. J Urol 2010;184(2):440-6. .

5. van Doorn B, Blanker M, Kok E, Westers P, Bosch J. Once nocturia, always nocturia? Natural history of nocturia in older men based on frequency-volume charts: the Krimpen study. J Urol 2011;186(5):1956-61.

6. Lee YJ, Jeong S, Byun S, Lee J, Han J, Kim K. Prevalence and correlates of nocturia in community-dwelling older men: results from the Korean longitudinal study on health and aging. Kor J Urol 2012;53(4):263-7.

7. Greibling T. Overactive bladder in elderly men: epidemiology, evaluation, clinical effects, and management. Curr Urol Rep 2013;14(5):418-25.

8. Nakagawa H, Niu K, Hozawa A, Ikeda Y, Kaiho Y, Ohmori-Matsuda K, Nakaya N, Kuriyama S , Ebihara S , Nagatomi R, Tsuji I, Arai Y. Impact of nocturia on bone fracture and mortality in older individuals: a Japanese longitudinal cohort study. J Urol 2010;184(4):1413-8. .

9. Van Kerrebroeck P. Nocturia: current status and future perspectives. Curr Opin Obstet Gynecol 2011;23(5):376-85.

10. Oelke M, Adler E, Marschall-Kehrel D, Herrmann TR, Berges R Nocturia: state of the art and critical analysis of current assessment and treatment strategies World J Urol 2014;32(5):1109-17.

11. Endeshaw Y. Correlates of self-reported nocturia among community-dwelling older adults. The J Gerontol Seri A: Biolog Sci Med Sci 2009;64(1):142-8.

12. Tinetti M, Speechley M, Ginter SF Risk factors for falls among elderly persons living in the community N Engl J Med 1988;319(26):1701-7.

13. Samaras N, Chevalley T, Samaras D, Gold G Older patients in the emergency department: a review. Ann Emerg Med 2010;56(3):261-9.

14. Gillespie L, Gillespie, WJ, Robertson, MC, Lamb, SE, Cumming, RG, Rowe, BH Interventions for preventing falls in elderly people. Cochrane Database Syst Rev 2009;2:CD000340.

15. Damian J, Pastor-Barriuso, Roberto, Valderrama-Gama, Emiliana, de Pedro-Cuesta, Jesus. Factors associated with falls among older adults living in institutions. BMC Geriatr 2013;13(1):6. 
16. Nakagawa H, Ikeda Y, Kaiho Y, Matsushita M, Hozawa A, Ohmori-Matsuda K, Tsuji I, Arai. Impact of nocturia on medical care use and its costs in an elderly population: 30 month prospective observation of national health insurance beneficiaries in Japan. Proc Int Cont Soc 2009:No.280.

17. Booth J, Lawrence M, O'Neill K, McMillan L Exploring older peoples' experiences of nocturia: a poorly recognised urinary condition that limits participation. Disabil Rehabil 2010;32(9):765-74.

18. Tikkinen KA, Johnson TM, Tammela TL, Sintonen H, Haukka J, Huhtala H, et al. Nocturia frequency, bother, and quality of life: how often is too often? A population-based study in Finland. Europ Urol 2010;57(3):488-98.

19. Agarwal A, Eryuzlu LN, Cartwright R, Thorlund K, Tammela TL, Guyatt GH, et al. What is the most bothersome lower urinary tract symptom? Individual-and population-level perspectives for both men and women. Europ Urol 2014;65(6):1211-7.

20. Rosen R, Holm-Larsen T, Kupelian V, Wein AJ. . Consequences of nocturia Postgrad Med 2013;125(4):38-46.

21. Markland AD, Vaughan CP, Johnson TM 2nd, Goode PS, Redden DT, Burgio KL. Prevalence of nocturia in United States men: results from the National Health and Nutrition Examination Survey. J Urol 2011;185(3):998-1002.

22. Lu Z, Gao Y, Tan A, Yang X, Zhang H, Mo L, et al. Increased high-sensitivity Creactive protein predicts a high risk of lower urinary tract symptoms in Chinese male: Results from the Fangchenggang area male health and examination survey. Prostate 2012;72(2):193200.

23. Yoshimura K. Correlates for nocturia: a review of epidemiological studies. Int J Urol 2012;19(4):317-29.

24. van Doorn B, Kok ET, Blanker MH, Westers P, Bosch JR. Determinants of nocturia: the Krimpen study. J Urol 2013;191(4):1034-9.

25. Chung M-S, Chuang Y-C, Lee J-J, Lee W-C, Chancellor MB, Liu R-T. Prevalence and associated risk factors of nocturia and subsequent mortality in 1,301 patients with type 2 diabetes. Int Urol Nephrol 2014;46(7):1269-75.

26. Kim JW, Oh MM, Yoon CY, Bae JH, Kim JJ, Moon DG. Nocturnal polyuria and decreased serum testosterone: Is there an association in men with lower urinary tract symptoms? Int J Urol 2014;21(5):518-23.

27. Obayashi K, Saeki K, Kurumatani N. Association between melatonin secretion and nocturia in elderly individuals: a cross-sectional study of the HEIJO-KYO cohort. J Urol 2014;191(6):1816-21.

28. Higgins J, Green SE. Cochrane Handbook for Systematic Reviews of Interventions. . Cochrane Collab 2011; Version 5.1.0(Available from www.cochrane-handbook.org. ).

29. Gulur DM, Mevcha AM, Drake MJ. Nocturia as a manifestation of systemic disease. BJU Int 2011;107(5):702-13.

30. Drake MJ. Should nocturia not be called a lower urinary tract symptom? Europ Urol 2015;67(2):289-90.

31. Kupelian V, Wei J, O'Leary M, Norgaard J, Rosen R, McKinlay J. Nocturia and quality of life: results from the Boston area community health survey. Europ Urol 2012;61(1):78-84.

32. Galizia G, Langellotto A, Cacciatore F, Mazzella F, Testa G, Della-Morte D, et al. Association between nocturia and falls-related long-term mortality risk in the elderly. J Am Med Dir Assoc 2012;13(7):640-4.

33. National Institute for Health and Care Excellence N, . NICE Guidelines for Falls in Older People. http://pathwaysniceorguk/pathways/falls-in-older-people/multifactorial-falls-riskassessmentaccessed October 2015. 
34. Nimeh T, Alvarez P, Mufarreh N, Lerner L. Nocturia: Current Evaluation and Treatment for Urology. Curr Urol Rep 2015;16(9):66.

35. Peyronnet $B$, Pradère $B$, Bruyère $F$. Management of nocturia: a nosological entity within lower urinary tract symptoms in men. Prog Urol 2014;24(2):80-6.

Figure caption

Figure 1: Directed acyclic graph summarising causal assumptions underlying nocturia. Confounding variables are shown in black boxes.

Table II: Summary of health risks associated with nocturia.

\begin{tabular}{|c|c|c|c|}
\hline Co-morbidity & $\begin{array}{l}1 \text { void / night } \\
\text { OR (95\% Cl) }\end{array}$ & $\begin{array}{c}\geq 2 \text { voids / pm } \\
\text { OR }(95 \% \mathrm{Cl})\end{array}$ & $\begin{array}{l}\geq 3 \text { voids / pm } \\
\text { OR }(95 \% \mathrm{Cl})\end{array}$ \\
\hline MENTAL HEALTH & & & \\
\hline $\begin{array}{l}\text { Depression } \\
\text { Male }\end{array}$ & $1.05(0.64-1.71)$ & $1.0(0.5-1.8)$ & $\begin{array}{c}2.8(1.5-5.2)-12.9(4.7-35.2) \\
2.68(1.45-4.93)\end{array}$ \\
\hline Female & $1.18(0.78-1.80)$ & $2.46(1.36-4.45)-3.4(2.2-5.3)$ & $2.63(1.60-4.32)$ \\
\hline Antidepressants & & $1.51(0.93-2.44)-2.8(1.3-6.3)$ & $2.6(0.7-8.8)$ \\
\hline Using SSRIs & & $1.2(0.5-2.9)$ & \\
\hline Male & & $2.2(1.1-4.5)$ & \\
\hline Female & & $5.4(1.5-19.7)$ & \\
\hline Anxiety & & $3.6(1.5-8.6)$ & \\
\hline Cognition & & $3.40(1.97-5.89)$ & \\
\hline High MMSE & & $0.88(0.82-0.94)$ & \\
\hline Male & & $0.64(0.46-0.88)$ & \\
\hline Female & & $0.96(0.92-1.00)$ & \\
\hline $\begin{array}{l}\text { Years of Education } \\
\text { CARDIOVASCULAR }\end{array}$ & & Female: $0.95(0.91-0.99)$ & \\
\hline Hypertension & $1.24(0.86-1.79)$ & $1.30(1.09-1.57)-2.68(1.55-4.63)$ & \\
\hline Male & & $1.4(1.0-1.9)$ & \\
\hline Female & & $1.62(1.03-2.56)$ & \\
\hline Orthostatic Hypoten. & & 2.0 & \\
\hline $\begin{array}{l}\text { Triglycerides }>150 \mathrm{mg} \\
\text { Heart Failure }\end{array}$ & $1.46(1.01-2.13)$ & $1.64(1.07-2.51)$ & \\
\hline Male & & $1.47(p=0.15)$ & \\
\hline Female & & $1.66(\mathrm{p}=0.10)$ & \\
\hline Cardiac Disease & & $2.28(1.72-3.03)$ & \\
\hline $\begin{array}{l}\text { MI } \\
\text { Lower limb swelling }\end{array}$ & & $1.87(1.14-3.08)$ & \\
\hline Male & & $1.95(1.17-3.25)$ & \\
\hline Female & & $1.67(1.02-2.75)$ & \\
\hline METABOLIC & & & \\
\hline Met Syndrome & $1.62(1.07-2.44)^{\star}$ & $1.63(1.13-2.34)-1.82(1.26-2.64)^{\star}$ & \\
\hline$<60$ years & $2.15(1.34-3.43)$ & $2.43(1.46-4.03)$ & \\
\hline$>60$ years & $0.68(0.33-1.39)$ & $0.93(0.46-1.88)$ & \\
\hline Obesity (18-79 yrs) & & $2.21(1.76-2.77)$ & \\
\hline Male & & $2.07(1.17-3.67)$ & \\
\hline Female & & $2.18(1.30-3.66)$ & \\
\hline $\begin{array}{l}\text { Type II Diabetes } \\
\text { Mellitus }\end{array}$ & $1.67(0.82-3.39)-3.37$ & $1.51(1.13-2.01)-2.62(1.40-4.92)$ & \\
\hline $\begin{array}{l}\text { Tremtus } \\
\text { Male }\end{array}$ & & $1.57(1.14-2.17)-1.71(1.12-2.60)$ & \\
\hline Female & & $1.29(1.05-1.57)-2.73(1.87-3.98)$ & \\
\hline Male $>65$ years & & $1.14(0.61-2.14)$ & \\
\hline Falls risk & & $2.25(1.21-4.14)$ & \\
\hline $\begin{array}{l}\text { High Melatonin } \\
\text { HEALTH STATUS }\end{array}$ & & $0.73(0.56-0.96)$ & \\
\hline
\end{tabular}




\begin{tabular}{lc} 
Poor & \\
Male & $2.7(1.1-4.8)$ \\
Female & $4.3(2.6-8.2)$ \\
Fair & $1.85(1.0-3.5)$ \\
Death & $1.60(1.01-2.57)-2.43(1.38-4.30)$ \\
Adjusted\# & $1.98(1.09-3.59)$ \\
INFLAMMATION & \\
$\uparrow$ Serum CRP & \\
Male & $0.81 \mathrm{mg} / \mathrm{L}: 1.64(1.18-2.27)$ \\
Female & $3.04(1.95-4.72)$ \\
Arthritis & $2.46(1.65-3.65)$ \\
Male & \\
Malignancy & $1.3(1.1-1.6)$ \\
\hline
\end{tabular}

\begin{tabular}{|c|c|c|c|}
\hline Co-morbidity & $\begin{array}{l}1 \text { void / night } \\
\text { OR }(95 \% \mathrm{Cl})\end{array}$ & $\begin{array}{l}\geq 2 \text { voids / pm } \\
\text { OR }(95 \% \mathrm{Cl})\end{array}$ & $\begin{array}{c}\geq 3 \text { voids / pm } \\
\text { OR }(95 \% \mathrm{Cl})\end{array}$ \\
\hline \multicolumn{4}{|l|}{ MEDICATION } \\
\hline Polypharmacy & & $1.12(1.04-1.21)$ & \\
\hline Diuretic & & $1.67(1.34-2.09)-2.66(2.13-3.34)$ & \\
\hline Male & & $1.25-2.11(1.43-3.82)$ & \\
\hline Female & & $1.59-1.94(1.44-2.80)$ & \\
\hline \multicolumn{3}{|l|}{ SLEEP } & \\
\hline Insomnia & & $2.92(2.11-4.05)$ & \\
\hline $2^{\circ}$ insomnia & & Fallers: 4.32 (1.50-12.41) & \\
\hline OSAD & & $2.44(1.14-5,23)-3.69(1.67-8.12)$ & \\
\hline Female & & $4.99(2.49-10.0)$ & \\
\hline \multicolumn{4}{|l|}{ Snoring } \\
\hline Male & & $1.49(1.0-2.22)$ & \\
\hline Female & & $1.76(1.17-2.64)$ & \\
\hline Restless Legs & & $1.18-2.44(1.14-5.23)$ & \\
\hline Male & & $2.91(1.30-6.52)$ & \\
\hline Female & & $2.86(1.41-5.83)$ & \\
\hline \multirow[t]{2}{*}{$\mathrm{RL}+2^{\circ}$ insomnia } & & $3.06(1.32-7.32)$ & \\
\hline & & Fallers: 2.95 (1.07-8.81)+ & \\
\hline
\end{tabular}

\# Adjusted for age, gender, BMI, diabetes, smoking history, coronary disease, renal disease, tranquilizers, hypnotics, diuretics

* Adjusted for age, race, socioeconomic status, physical activity, smoking, alcohol consumption, LUTS medications

+ without difficulty returning to sleep

Table III: Summary of falls risks associated with nocturia

\begin{tabular}{lcccc}
\hline Variables & Any nocturia & 1 void / night & $\begin{array}{c}\geq 2 \text { voids / pm } \\
\text { Risk }(95 \% \mathrm{Cl})\end{array}$ & $\begin{array}{c}\geq 3 \text { voids / pm } \\
\text { Risk }(95 \% \mathrm{Cl})\end{array}$ \\
\hline Falling & $1.3(1.01-1.88)-$ & $1.46(0.83-2.57)$ & $1.84(1.05-3.22)$ & $1.31(1.05-1.64)-2.15$ \\
& $2.8(1.82-4.30)$ & & $(1.04-4.44)$ \\
Occasional & $1.75(1.12-2.75)^{\star}$ & & & $1.28(1.02-1.59) \#$ \\
Frequent & $1.1(\mathrm{p}=0.73)$ & & & \\
Incident Fall & $3.0(\mathrm{p}=0.065)$ & & & $1.27(1.01-1.6)$ \\
Hip Fracture & & & & $1.8(1.1-3.0)$ \\
Male & & $0.97(0.73-1.28)$ & $1.36(1.03-1.8)$ & \\
All fractures & $1.6(1.4-1.8)$ & $1.40(0.77-2.55)$ & $1.16(0.63-2.15)-$ & \\
& & & $2.01(1.04-3.87)$ & \\
Male & & & $2.07(0.95-4.51)$ & \\
Female & & & $2.61(0.76-8.95)$ & \\
\hline
\end{tabular}


\# adjusted for diabetes and slow gait * adjusted for age and sex

Table I: Summary of patient report of the impact of nocturia

\section{Frustration}

Nuisance

Annoying

Unpredictable

Painful

No response to self-imposed fluid restriction

Disruption disproportionate to amount of urine passed

Consequences

Not being able to fall back to sleep

Irritability

Reduced concentration

Restless nights

Increased awareness of risk of falling

Feeling slow and sluggish on waking in the morning

Irritability

Mindset

Fear of incontinence

Limits social participation

Nocturia too trivial to talk to doctor about

A condition to cope with rather than cure

Normal part of ageing 
Figure 1: Directed acyclic graph summarising causal assumptions underlying nocturia. Confounding variables are shown in black boxes.

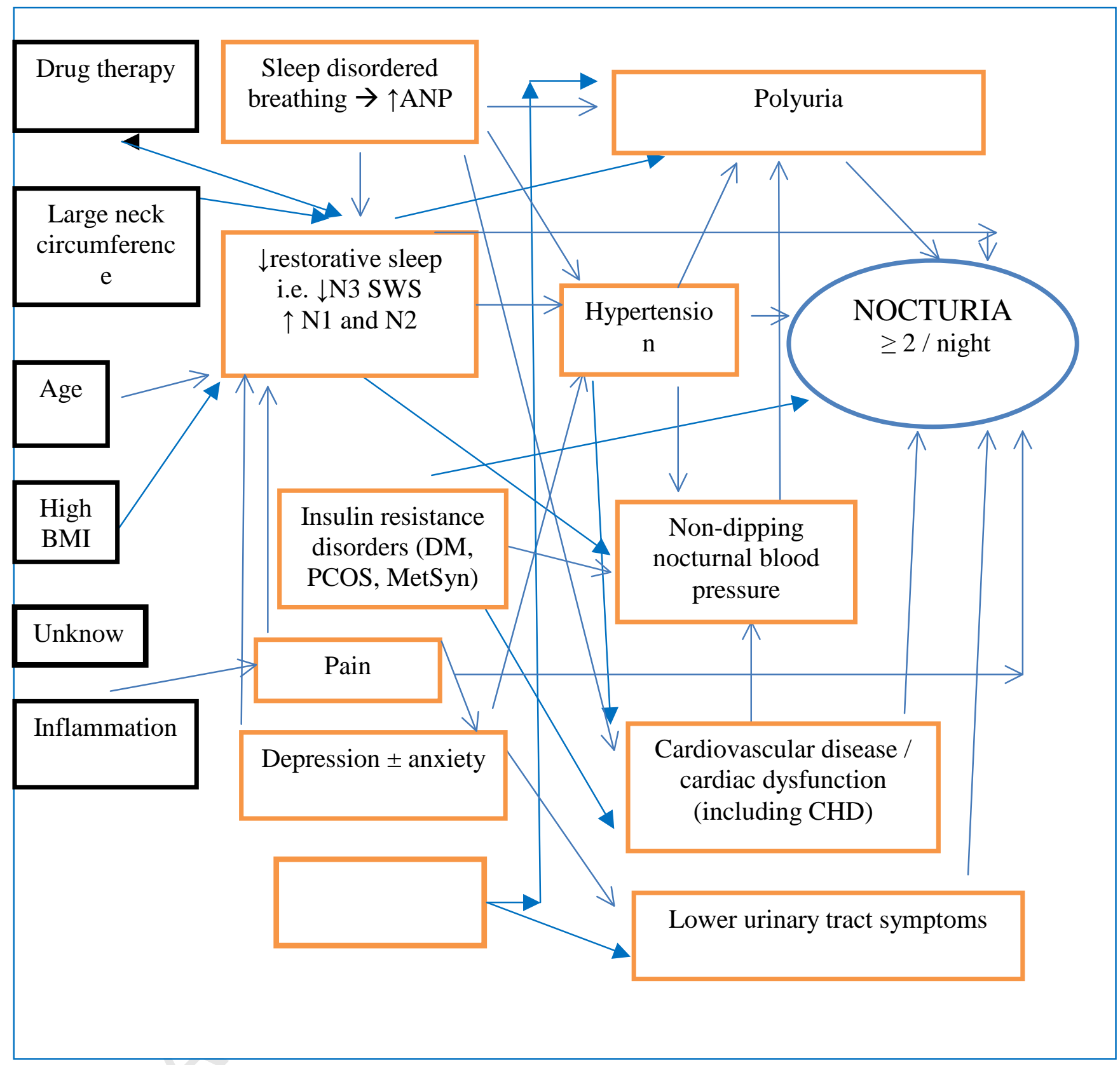


nau23000-fig-0001 . 


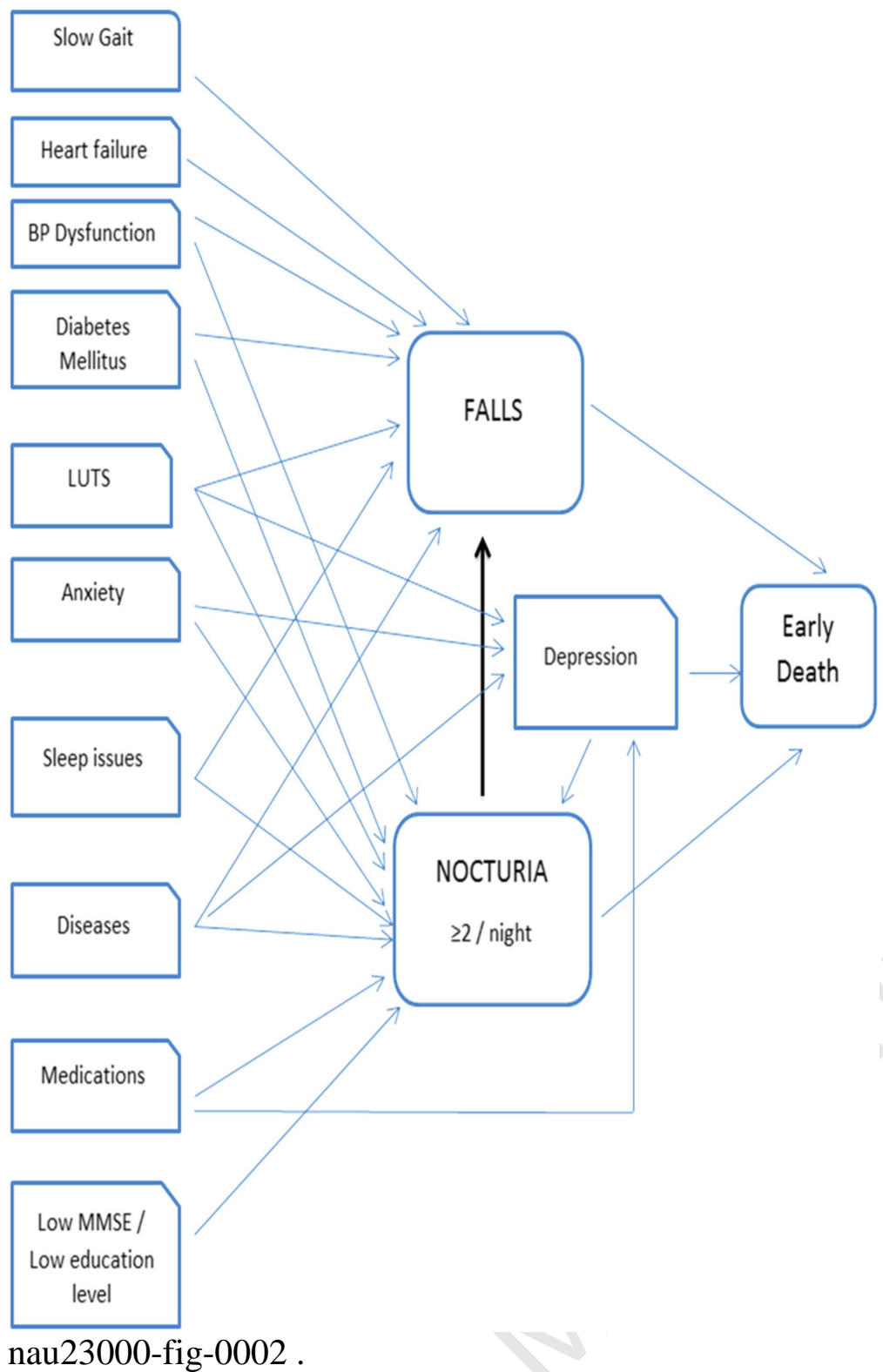

nau23000-fig-0002 . 


\section{University Library}

\section{- M M I N E R VA A gateway to Melbourne's research publications}

Minerva Access is the Institutional Repository of The University of Melbourne

Author/s:

Bower, WF;Whishaw, DM;Khan, F

Title:

Nocturia as a Marker of Poor Health: Causal Associations to Inform Care

Date:

2017-03-01

Citation:

Bower, W. F., Whishaw, D. M. \& Khan, F. (2017). Nocturia as a Marker of Poor Health: Causal Associations to Inform Care. NEUROUROLOGY AND URODYNAMICS, 36 (3), pp.697-705. https://doi.org/10.1002/nau.23000.

Persistent Link:

http://hdl.handle.net/11343/291150 